\title{
Detection of Human Under Earthquake Rubble
}

\author{
S Lourdu Jame, Y Jeyashree, S.Srikantan, P. Jais Duraimani, Mohamed Dhageer
}

\begin{abstract}
Natural calamities like earthquake,flood, volcanic eruptions, landslides, avalanches, etc are unavoidable circumstances .Occurance of such natural ailments is unpredictablecausing huge damageto resources and structures which is unavoidable .Measurement, eleventh hour detection, precautionary and rescue methods are onlypossible options .A proper rescue can do milestones in savinglife of people under such circumstances. In messina region of Newyork death tolls were 5000 during earthquake, nearly halfthe population. In Utharkhand during 2013 a landslide caused lots of people buried under earth. Newspaper report stated that if people were detected earlier death tolls would have been quite low. In this paper we design a rescue robotic platform which can act more quickly in detection location mapping diagnosing status post earthquake, avalanches andlandslides. The robot platformdesigned isfor disastermanagementsystemduringavalanches, earthquakes, and landslidesfor accurate andfasterdetectionofhuman trapped inside without live interaction and notcausingdamagedue to increasedload of rescuer onthemwhiledetectionusinga robotic platformcontrolled remotely.
\end{abstract}

Keywords- Microwave Doppler sensor, GPS, Raspberry PI,IoT,Stepper motor, WiFi.

\section{INTRODUCTION}

In modern era due to high population indexcitiesare densely populatedina countrymakes any disaster, much more deadly. Complexity to deploy rescue teamsincreases asthe large number of huge, vastinfrastructures of a city andreduces the effectiveness of the rescue teams greatly. Disaster sites are complex and dangerous. In human rescuer weight of man walking on collapse to detectcan cause threat to buried humans .There isa great threat to rescue workers as well assurvivorsin such debris and ruins .A rescue robot can be of great help to detect human beings . The weight of human rescueroverloads and thepressure of human struck beneath heavy structures increases par bearable pressure causing death. So a human with walk stick or detector is a poor solution. Similar happens to acoustic detectors and optical devices. The Rescue Robot can navigate deep into the rubble to search for victim by the use of temperature sensor but they are prone to go out of range. In recentdays dogs are employed more to detect human trapped under building rubble but dogs senses by smell and are prone to detect dead bodies earlier than alive people due to high sensed smell

Revised Version Manuscript Received on10, September 2019.

S Lourdu Jame, Assistant Professor, EEE Department, SRM Institute of Science and Technology, Chennai, Chennai, Tamilnadu, India. (Email: lourdujame@gmail.com)

Y Jeyashree, Associate Professor, EEE Department, SRM Institute of Science and Technology, Chennai, Tamilnadu, India.

S.Srikantan, B.Tech Final Year Students, SRM Institute of Science and Technology, Chennai, Tamilnadu, India.

P.Jais Duraimani, B.Tech Final Year Students, SRM Institute of Science and Technology, Chennai, Tamilnadu, India.

Mohamed Dhageer, B.Tech Final Year Students, SRM Institute of Science and Technology, Chennai, Tamilnadu, India. measurement values on dead bodies than alive humans and consumes time under situation when each minute may counts a death toll.

The exact location is very important to rescue the people and to save more lives. So the life saving devices are very needed to protect or save people from earth Quake in a efficient manner with a short span of time. Microwave radar based systems have very high accuracies in humandetection with longerrange of detection .GPS can be used to track location information

\section{OBJECTIVE}

Designaapparatusfor rescuing victims buried (or) trapped under earthquake rubble a robotic system which will be really effective to solve problem has be designed and tested in test environment.

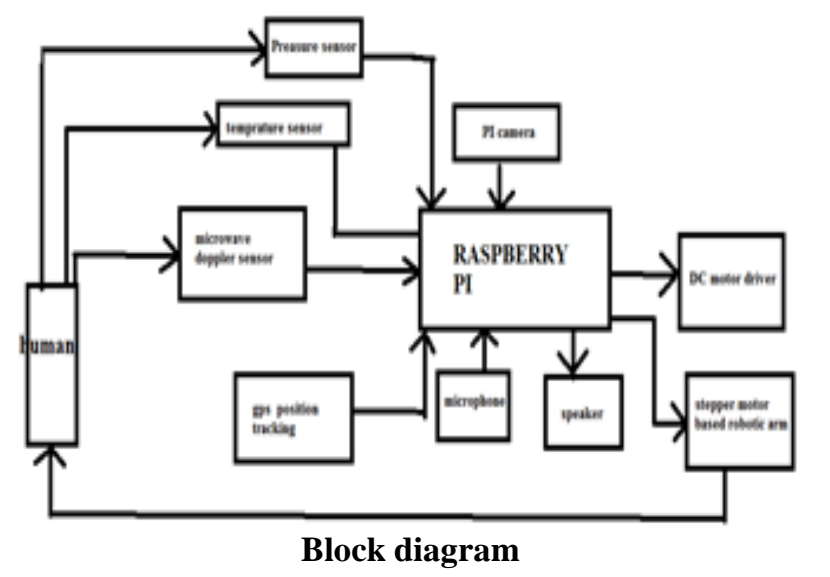

\section{III.METHODOLOGY}

\section{Human-controlled roboticsystem:}

It is a human-robotinterfaced systemcapable of doing multipleprocesses that an human does and modification in structure for specification purpose can act much better theira human without loss of life. Reason for development of human system:

-Direct human inter vension is not possible in many cases.

-The worker or rescuer may be at risk of impairment or loosing life.

-Worker may unknowingly cause damage or impairment to human or structures in proposed site

-Level of sensing, recovery ,fast action or responseof a human ispoor as compared toaspecifically designed hu-ro system.

Published By:

Blue Eyes Intelligence Engineering

\& Sciences Publication 


\begin{tabular}{|l|l|}
\hline Human & $\begin{array}{l}\text { Human-Robot interfaced } \\
\text { system }\end{array}$ \\
\hline eyes & Camera \\
\hline ears & Microphone \\
\hline mouth & Speaker \\
\hline hands & $\begin{array}{l}\text { Stepper motor based } \\
\text { function specific hand } \\
\text { structure(mop type hand } \\
\text { for avalanche removal) }\end{array}$ \\
\hline legs & $\begin{array}{l}\text { Stepper motor based } \\
\text { function specific leg } \\
\text { structure(rover type for } \\
\text { movement through } \\
\text { cluttered structures) }\end{array}$ \\
\hline $\begin{array}{l}\text { Other sensors(nose- } \\
\text { smell sensor, } \\
\text { temperature and } \\
\text { pressure sensor-skin } \\
\text { surface and other aux } \\
\text { sensor) }\end{array}$ & $\begin{array}{l}\text { Sensor are function specific } \\
\text { like ultrasonic sensor } \\
\text { temperature and pressure } \\
\text { sensor,Gps }\end{array}$ \\
\hline $\begin{array}{l}\text { Human brain } \\
\text { Hum }\end{array}$ & $\begin{array}{l}\text { Human brain interfaced } \\
\text { through IoT concept }\end{array}$ \\
\hline
\end{tabular}

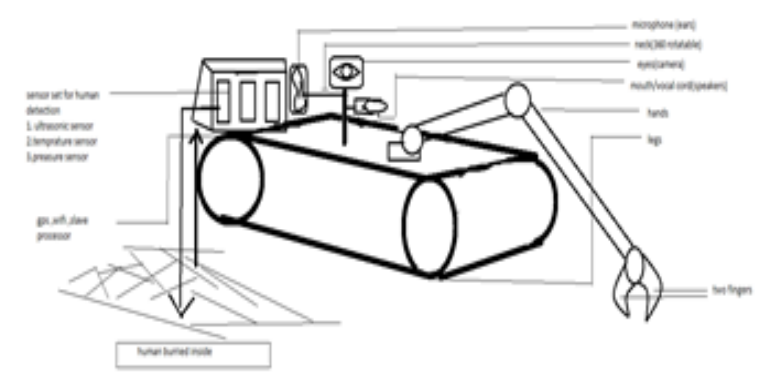

Why not a humanoid robot:

1. Cost of making a humanoid robotic structure which can self-thinkis very high.

2. Ittakes years to develop a human equivalent .Whilehuman-robotic interfacedsystem takes very less time to develop and least cost while efficiency increases.

So arobotic platform equivalent to human physique in action with additional function specific featuresoperated by human brain is muchbetter than human as well as pure humanoid robots taking into performance, economic, controllability, ease of making, lesser duration of production modification.

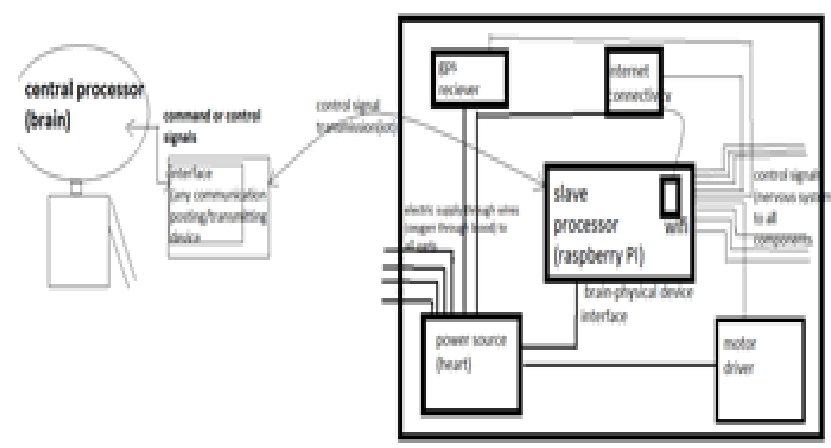

\section{Detection of human:}

Existing systems used PIR sensor for humandetection. Live human body emits thermal radiation it is received and manipulated by the PIR sensor to detect humans. The common PIR motion sensors widely used in burglar alarms and security lightswhich detects only movements within its detection range. Althoughthe range of sending is not poor butsensitivity lags a lotasemittedradiationsfrom human body gets attenuatedand insufficientto trigger levels of PIR sensor .We deploymicrowave Doppler sensor which has a very high range of accessand workson Doppler principle. Instead of sniffing the black body radiation from a moving person, this sensor uses a "microwave Doppler radar" technique to detect moving objects.

In recent earthquake in Canada microwave based radarsystemdeveloped by NASA has been deployedafter when dogs weren't able to detect . The device was immovable worked on radar communication and has very high level of sensitivity. Microwave based human detection techniques are far superior than other detection methods. We designweb page operable by far user and work based on IoT concept in prototype model while while radar communication is preferred in real-time system.[2]

Microwave Doppler sensor used in prototype modelhas a sensitivity range of $\sim 7$ meters. When triggered, its TTL-level output (OUT) pin will switch from LOW (0 V) to HIGH (3.3 $\mathrm{V})$ for a finite time ( 2 to $3 \mathrm{~s}$ ) before returning to its idle (LOW) state.

\section{3.slave processor andconnected sensors:}

\section{I.RASPBERRY PI:}

It is a higher capabilitycontroller equivalent to minicomputer with core ARM Cortex A7Video Core IV GPUas its processor and with 1GB ram memory. Raspian OS is the software used as operating systemwhich can be loaded in a sim card and inserted in the controller for booting the device. It has in-built WiFidevice and 40 pins among which 32 are GPIBandsensors can be connected to it. It receivesmeasurements and sensed valuesfromvarioussensorswhich it processes on to determine low or high on output sensorsWhile simultaneously transmitting data to user. Various sensors canbe solderedand programmed in pythonto retrieve values or to spit outforfunctioning of output sensors. Any display device can be connected to program it or run the program while a vnc media layer as display portal connected through WiFi is ideal choice.[6]

\section{II .USB CAMERA:}

Camerais used to record video andlive stream it to far away user. User instead of going to the location views it through web page. Raspberry PIcamera has been specificallydeveloped for interfacing to this controllerand has high clarity of $5 \mathrm{Mp}$ working without buffering issues as in webcam .It act as eyes to the proposed system [4]

\section{III .SPEAKER :}

It acts like electric signal to sound converter. Like a human having vocal cord whose momentsproduces varioussounds a speakerconsist of aluminumfoil. Aluminumfoil moves asresponse toelectricalsignalproducing sound of various tone according to its input electrical signal levels .It acts like a mouthcapable of communicating. It is used for detector to 
communicate with trapped humansas well as rescuers.

\section{IV.MICROPHONE:}

It is similar tospeaker having an a mechanism which vibrates as that of eardrum in humansaccording to sound level .The vibrationsareconverted into equivalent electrical impulseswhich are transmitted toprocessor.

\section{DC MOTOR DRIVE and DC motor:}

The L293D is a 16-pin Motor Driver IC which can control a two sets of DC motors simultaneously in any direction. The L293D is designed to provide bidirectional drive currents of up to $600 \mathrm{~mA}$.A motor driver uses a larger chip or discrete FETS which are able to handle larger amounts of current and higher voltages than the standard $5 \mathrm{~V} / 3.3 \mathrm{~V}$ from a microcontroller pin. Two wheels are driven by pair of $\mathrm{dc}$ motors which are interfaced to the arduino yun through L-293 dual H-bridge

\section{VI.STEPPER MOTOR:}

Stepper motor provides predefined motion in stepsfor each excitation. Stepper motor is made to provide robotic arm feature .When button in web page is clicked control signals are transmitted which decides forward or backward moment. In case of landslides and avalanches it is used for removing mud or glacier iterativelyhence reducing weight thus pressure on buried person.

\section{Acquiring location and health status:}

\section{GPS:}

It is essential to track exactly the location of the trapped human for the rescue process. Whenever the Robot platform is instructed to shift the position, Raspberry PIpolls the GPS sensor to get the restored GPS position and then when it is instructed to send the GPS tracking then this location is sent to the Data queue of the cloud service bus. This data is later acknowledged byAndroid application which loads the UI accordingly.

This NMEA string result from the GPS receiver consists of various guidelines distinguished by factors like longitude, latitude, altitude, time, etc.[5]

\section{II.TEMPRATURE:}

Temperature is an important parameter for assessing the health status ofperson. Lm35 temperature sensor is used. The temperature limits for survivalranges from 28-41 above or below which Hyperthermia occurs. Under such situation immediate rescue would be required.

\section{III.PREASURE SENSOR:}

Human body bearablepressure ranges till 70 times atmospheric pressure that is 140 pounds per sq inch above which life is not possible due to very high weight on body.Bmp180 pressure sensor is used to measure the preasure on human. It is barometric type.

The values from temperature and preasure sensor are used to monitor health status of individual to know how long he can sustain as well as emergency resque requairements.

\section{5. structure and movement:}

Disaster location has colapsedstructures and ruins hence surface is cluttered andhighly uneven .Moment or locomotion in such sitesis much complex and required specific designs. We use rovertype structure which are made of beeds for prototype model for propulsion in such odd rising and valley surfaces. Rover is coupled to dc motor which is interfaced withraspberry PI.At a particular webpage moment buttons will be available clicking on them can move through such cluttered surfaces. [7]

\section{IoT ,web page development and accessing content:}

A webpage of particular address iscreated with live streaming, moment controls and arm control usinghtml and PHP. Details of temperature ,pressure andhealth status is alsodisplayed.

The information to raspberry pi is posted on internet platform through Wifi connection which is accessible from anywhere around the world by typing the portal address. Since network availability may not presentpost disaster in such sites a radar based communication is suggested in real time system.

By typing the port address on browser anyone can access the information from anywhere .[4]
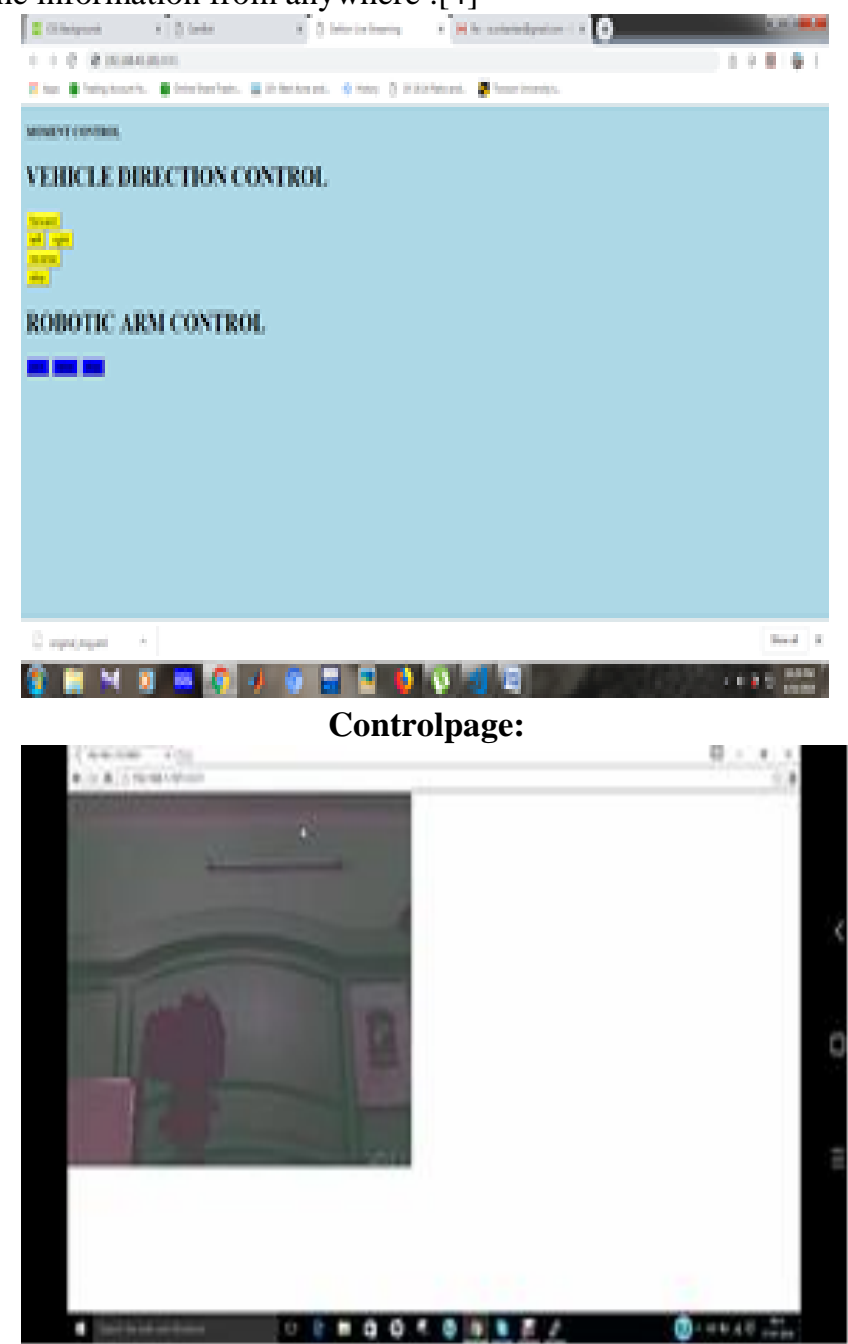

Videolivestream page:

WEBPAGEOFPROTOTYPE MODEL: 


\section{IV.WORKING}

MicrowaveDoppler sensor attached to RASHBERRY PI sense probability of rescuing victims buried (or) trapped under earthquake rubble if not detected then usingGPS based mobile control systemits motion is controlledto move to adjacent area for human life detection in adjacent area. Motion is throughH-bridge drive circuitsthrough dc motor for propulsion. If detected then RASH BERRYPI sends data to the central system or mobile phone and using GSM service sends data about location of target person under debris to far away userand an alert signal torescuers. Simultaneously RASHBERRY PI switches on web cam which captures images of current position and surrounding. Ifhumans are detected / pictures of humans are captured then again it sends alert signal. These data is sent to far away host computer using IOT .

\section{V.SIMULATION\& RESULTS}

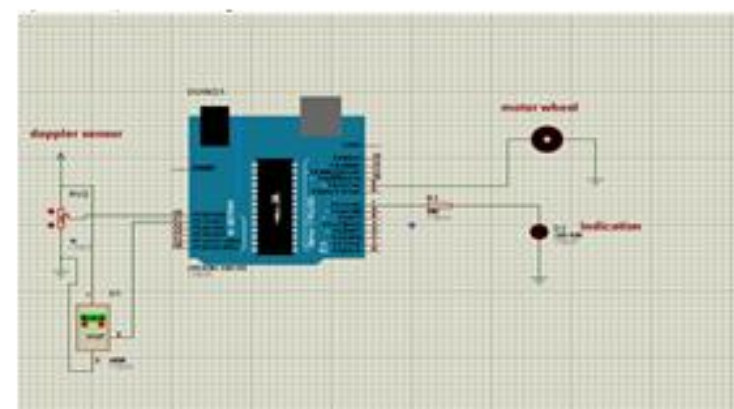

A simple simulation ofdopplersensors andtemperature

Sensorinterfaced with controlleriscompleted in Proteus software .When thedistanceofvictim raised below preset valuebuzzer sirens and wheel stops.

Arduino controller is usedfor simplicity.

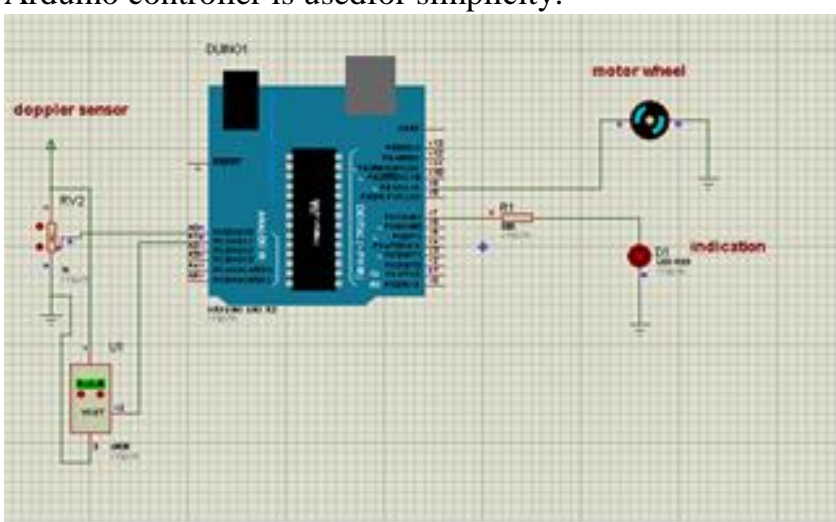

We can see that buzzer sirens whenDopplergetsexcited by presenceof human inthe second image. Distance of human from sensor can be variedbyvarying using + and - symbol displayed near Doppler sensor.

\section{CONCLUSION}

A prototype model of robotic system capable ofhuman live detection post earthquake with location tracking ,live streaming ,environmental condition monitoring is done using raspberry PI as intermediate processor. The proposed system has covered advantages of many existing systems and tested. The system is also capable of doingrescue operations in landslides and avalanches .In real time system it is better to adopt radar communication rather than IOT based as Internet connectivitywill be poor in these sites.

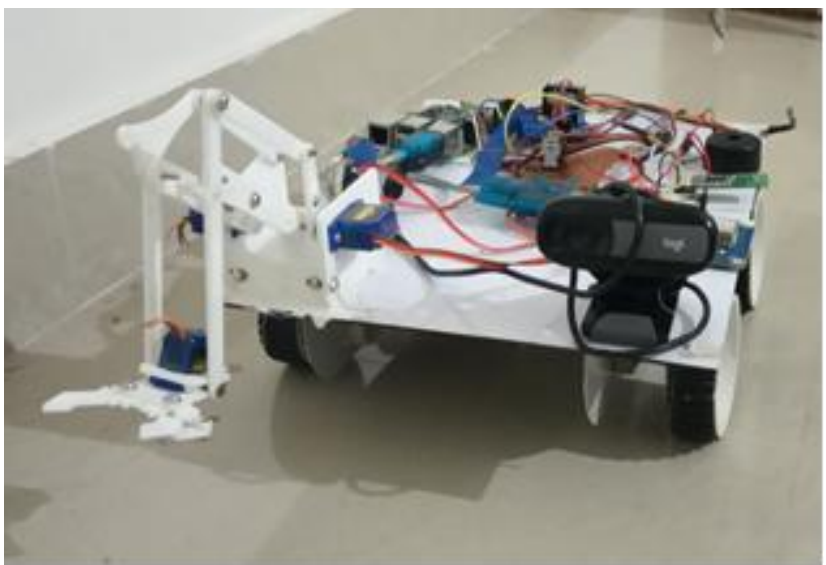

\section{REFERENCE}

1. Jeffrey A. Nanzer ,'A Review of Microwave Wireless Techniques for Human Presence Detection and Classification' ,IEEE, Jan 30, 2017

2. Zade Gauri N., 2Mr. Badnerkar S.*S.' A Modern Microwave Life Detection System For Human Being Buried Under Rubble', IJAERS/Vol. I/ Issue I/October-December, 2011

3. Prashant G. Salunkhe, Sahil Y. Shaikh 'Video Surveillance Using Raspberry Pi Architecture', International Conference on Computing, Communication, Electrical, Electronics, Devices and Signal Processing (CCEEDS) and International Conference on Electrical, Electronics, Engineering Trends, Communication, Optimization and Sciences (EEECOS/E3COS),March 2015

4. 1MANDAR KULKARNI, 2ABHISHEK MISHRA, 3PRANJAL BARABDE ,'IOT Based Multifunctional Robot Using Raspberry-Pi' , International Journal of Advances in Electronics and Computer Science, ISSN: 2393-2835 Volume-4, Issue-3, Mar.-2017

5. Amany El Gouhary, Richard Wells , Anthony Thatcher, 'GPS Tracking System'April 28, 2006

6. Vivek Gupta1, Vikramsingh Mane2, Manash Ranjan Pradhan3 \& Kapil. B. kotangale4 ,IOT Based Car Automation Using Raspberry Pi-Imperial Journal of Interdisciplinary Research (IJIR) Vol-3, Issue-4, 2017

7. D. Kalaiarasi1, Pavithra .S2, Pratheeba .S3, PriyaadharshiniIoT BASED MOTION CONTROL SYSTEM OF A ROBOTIC CAR ,International Research Journal of Engineering and Technology (IRJET) e-ISSN: 2395-0056 Volume: 05 Issue: 03 | Mar-2018. 